\title{
Rehydration ratio of fluid bed-dried vegetables
}

\author{
BOBIĆ Z, BAUMAN I and ĆURIĆ D \\ Faculty of Food Technology and Biotechnology, University of Zagreb, \\ Pierottijeva 6, 10000 Zagreb, Croatia \\ e-mail: ibauman@pbf.hr
}

MS received 25 June 2001; revised 30 November 2001

\begin{abstract}
Fluid-bed drying of vegetable pieces has been investigated. The vegetables used have been potatoes, parsley roots, celery roots and carrots of various dimensions. Starting water content was: potatoes $78 \%$, parsley roots $85.1 \%$, celery roots $93.6 \%$, and carrots $88.6 \%$. Temperatures of fluidisation have varied from $60^{\circ}$ to $100^{\circ} \mathrm{C}$ at velocities of $0.71 \mathrm{~ms}^{-1}$. The goal has been to obtain dry vegetables with $6 \%$ to $10 \%$ water content and of good rehydration quality. Experimental data (bed height, gas temperature and velocity, pressure drop over the bed, drying time) have been measured and relevant values have been calculated. The results have shown that drying of vegetables in a fluidized bed produces dry vegetable pieces of excellent quality in a much shorter time than in continuous belt-dryers which are generally used.
\end{abstract}

Keywords. Fluid-bed drying; fluidisation; dried vegetables.

\section{Introduction}

In the food processing industry the heat treatment of vegetables is a very important operation. The objective is to produce dried food that is shelf-stable, and microbiologically safe, with minimal degradation of nutrients and sensory properties. The heating rate of solids is generally slow. The advantage of a high temperature-short time process decreases as the size of the piece increases. There are some difficulties in assessing the heat transfer ratio to suspended pieces and in determining the resident time distribution (Le Maguer \& Jelen 1986)

The prerequisite for a technologically sound process of drying is a knowledge of biological, physical, chemical and other characteristics of food materials and products and their behaviour under various conditions.

One of the promising drying processes is drying of minced vegetables in a fluidized bed, due to better heat and mass transfer, shorter drying time, better quality of products obtained and shorter reconstitution time (Bobic et al 1986).

Drying experiments have been conducted to study fluid bed drying times for various vegetables and the hydrodynamics of the fluid bed. Composition, mass density and temperature

\footnotetext{
${ }^{*}$ A list of symbols used is given at the end of the paper
} 
are the main factors or process conditions affecting thermal properties (Troller \& Christian 1978). Only composition, density and temperature affect the thermal conductivity and thermal diffusivity. Specific heat is affected by composition and process temperature (Kožiškova 1983). Changes in nutritional characteristics of dried materials have been investigated. It is possible to shorten the drying time and produce a very open structure of dry pieces that hastens drying and gives better rehydration times.

\section{Materials and methods}

The fluidised bed-drying column is a glass cylinder of $0.205 \mathrm{~m}$ diameter and $0.900 \mathrm{~m}$ height. The fluidisation grid is placed $0.6 \mathrm{~m}$ from the top (figure 1). The column is made of four glass cylinders connected by flanges and rubber gaskets. A teflon ring (of the same diameter as the inside of the cylinder) is inserted into the column, $0.2 \mathrm{~m}$ from the bottom. A stainless steel ring is placed within this ring, carrying the fluidisation grid. Connections for temperature and pressure drop measurements are provided. Air is introduced through the conical bottom part from a centrifugal fan through a pipe of $0.104 \mathrm{~m}$ diameter. The fan is equipped with a monophase electrical motor with continuous automatic speed regulation. Air is introduced through a side entrance at the bottom of the column. Airflow is measured at the entrance to the column and in the middle of the column by an electrical anemometer (EDRA 4, AirFlow Corp.) with ranges of 0.12-1.0, 0.75-2.5, 2.0-20 and 7.5-25. The precision of this instrument is $\pm 2 \%$. The temperature measurement connections are introduced through side openings in the glass cylinders. In the course of drying, the temperatures are measured by a $\mathrm{NiCr} / \mathrm{Ni}$ thermocouple and a digital temperature indicator with a range of $-65^{\circ}$ to $150^{\circ} \mathrm{C}$. To get a flexible range of increasing air temperatures, a special electric heater, with automatic temperature control, has been constructed. It contains six 2.3 kilowatt electrical heaters in a thermally isolated box. The heaters are spaced so that good mixing of air and good heat transfer is possible in a short time. Two-point automatic regulators are built into the heater and connected to the outlet temperature-measuring device. The pressure drop is measured

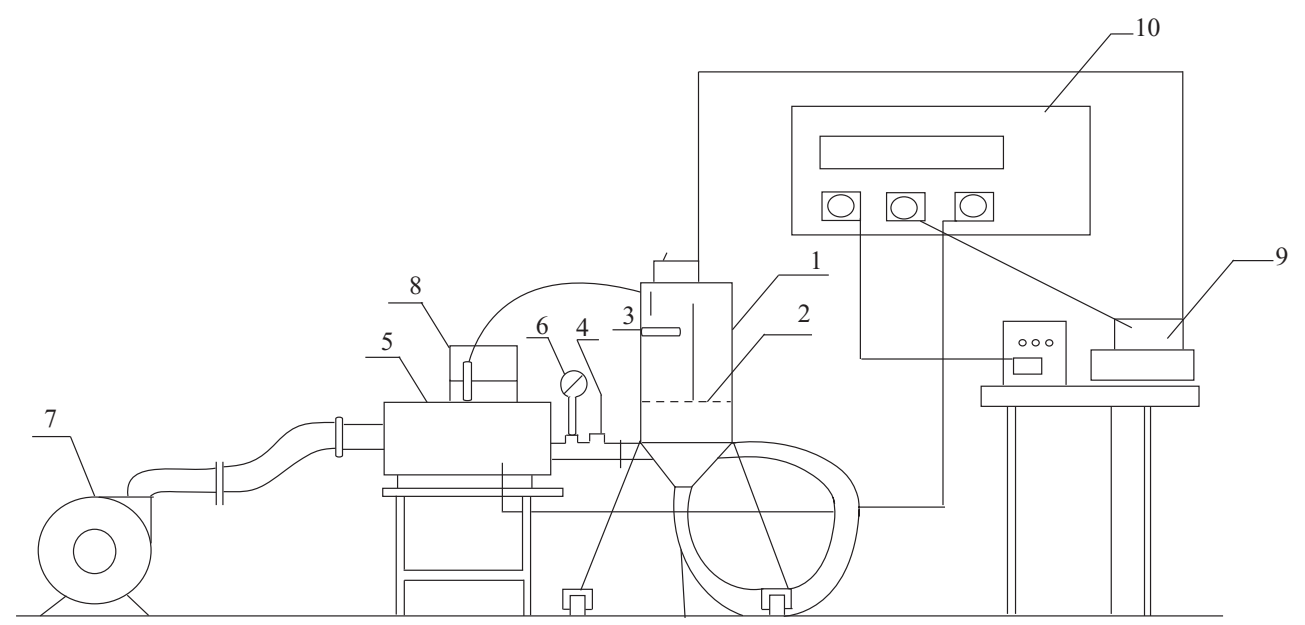

Figure 1. Schematic representation of experimental apparatus (circular fluid bed column). (1) Plastic column; (2) fluidization grid; (3) heater; (4) thermometers; (5) electric heater; (6) anemometer; (7) fan; (8) thermocouple; (9) regulator; (10) automatic heat controller. 
by metallic pipes of short diameter placed in position such that pressure drop over the grid and in the fluidised bed can be measured. The pressure drop is measured statically with a micromanometer (AirFlow Corp.), with an operating range of 0-2500 Pa. The column can be rotated on a pivot for emptying and recharging.

The vegetables used so far for drying have been carrots, parsley roots, celery roots and potatoes. Each sample was prepared in a different way, because of its specific content. Sample preparation is very important for the best drying results, while the drying times are more or less the same for all vegetables studied even though the rehydration times are shorter.

Carrots were blanched for 4 minutes at $90^{\circ} \mathrm{C}$, then dried and cut into cubes and frozen. For drying experiments, samples were then thawed at $180^{\circ} \mathrm{C}$ for 145 minutes. Before drying, samples were thermally treated - boiled in water or in $\mathrm{NaCl}$ solution for 3.5 minutes at $90^{\circ} \mathrm{C}$.

Parsley samples were boiled in water for 15 minutes or in $\mathrm{NaCl}$ solution of $0.5 \%$ or $1 \%$ for 20 minutes. Blanching time needed was determined for every sample on the basis of the peroxydase test and was 3 minutes at $93^{\circ} \mathrm{C}$ for parsley. To retain the white colour of parsley and celery roots, diced samples were treated with $\mathrm{SO}_{2}$ generated by burning sulphur rods in a closed glass vessel for 25 to 30 minutes.

Celery roots were blanched at $93^{\circ} \mathrm{C}$ for 3 minutes, cooked for 15 minutes in water and then for 15 minutes in $1 \%$ solution of $\mathrm{NaCl}$.

The main characteristics of the vegetables and important parameters of each type are shown in table 1.

Potato samples were blanched in water at $80^{\circ} \mathrm{C}$ for 150 seconds with an addition of $0.5 \mathrm{~g} / \mathrm{kg}$ of ascorbic acid. Blanched potatoes were cooled in running water and wiped dry.

The pieces, before drying, are treated with a small quantity of starch solution (2-5\%) that forms a thin dense film on the surface. The pieces are than treated for a short time in a fluid bed at a much higher temperature than that used in normal drying. The high starting temperature "shocks" the surface, closes and hardens the coating, and the water inside the piece is converted partially to superheated steam that, after a certain internal pressure is reached, by quick expansion destroys the film and opens up the inside structure of the piece. After this first "shock" drying, the pieces are dried at the usual fluid-bed temperature up to the specified water content.

In fresh and blanched vegetables, dry matter and carotene (especially melanoid) were determined. Carotenes and melanoids are used as indicators for vegetable browning (AOAC 1995; AACC 1998).

All samples, except potatoes, were cut into cubes of $7 \times 7 \times 7 \mathrm{~mm}$, and exposed to $\mathrm{SO}_{2}$ for 20 minutes in a dessicator to preserve the original colour. There were no $\mathrm{SO}_{2}$ residues found in the final products after drying. Potatoes were cut into pieces $5 \times 5 \times 5 \mathrm{~mm}$ in size.

Table 1. Characteristics of vegetable used.

\begin{tabular}{lccccc}
\hline Sample & $\begin{array}{c}\text { Vegetable } \\
\text { type }\end{array}$ & $\begin{array}{c}\text { Dimensions } \\
(\mathrm{mm})\end{array}$ & $\begin{array}{c}\text { Sugar } \\
\text { content }(\%)\end{array}$ & $\begin{array}{c}\text { Vitamin C } \\
(\mathrm{mg} / 100 \mathrm{~g})\end{array}$ & $\begin{array}{c}\text { Dry matter } \\
(\%)\end{array}$ \\
\hline Potato & Fresh & $5 \times 5 \times 5$ & 18.9 & 10 & 7.9 \\
& Dried & - & 8.12 & 4.5 & \\
Carrot & Fresh & $7 \times 7 \times 7$ & 9.1 & 6.0 & 9.66 \\
Celery & Dried & - & 5.4 & - & 86.6 \\
root & Fresh & $7 \times 7 \times 7$ & 4.3 & 7.0 & 14.4 \\
Parsley & Fried & - & 1.8 & - & 95.0 \\
root & Dresh & $7 \times 7 \times 7$ & 8.5 & 172 & 22.8 \\
& Dried & - & 2.3 & - & 92.1 \\
\hline
\end{tabular}


Table 2. Rehydration times for different vegetables.

\begin{tabular}{lc}
\hline Vegetable & $\begin{array}{c}\text { Rehydration time } \\
\text { (min) }\end{array}$ \\
\hline Carrot & $15-20$ \\
Parsley root & $10-15$ \\
Celery root & $25-30$ \\
Potato & $8-13$ \\
\hline
\end{tabular}

In the treated samples, dry matter and rehydration ratios were determined and these are shown in table 2.

On the basis of the experimental data and that from the literature the following formulae for drying time, drying speed and final moisture content have been used.

Drying time:

$$
\tau=\left(x_{1}-x_{r}\right) / N \quad(\mathrm{~s}) .
$$

Moisture:

$$
x=W_{\text {ost }} / m_{\text {d.m. }}\left(\mathrm{kg}_{\mathrm{H}_{2} \mathrm{O}} / \mathrm{kg}_{\mathrm{d} . \mathrm{m} .}\right) .
$$

Drying speed:

$$
N=C_{1}\left(\frac{v \rho x_{1}}{m_{\text {d.m. }} \rho_{1} v_{1}}\right) \beta \quad\left(\frac{\mathrm{kg}_{\mathrm{H}_{1} \mathrm{O}}}{\mathrm{kg}_{\mathrm{d} . \mathrm{m} .} \mathrm{S}}\right) .
$$

Values of the constant $C_{1}$ were between $1.58 \times 10^{-5}$ and $2.09 \times 10^{-5}$. Values of the constant $\beta$ were between 1.15 and 1.26. Both constants depend on the nature of the treated material. The exact constants were calculated for each of the materials.

The formulae developed could be applied to all the materials tested and the coefficients do not depend on the size or the shape of the pieces. The organoleptic characteristics as determined for rehydrated materials are presented in table 3.

Rehydration ratio:

$$
R_{0}=M_{r} / m_{\text {ost }} .
$$

Table 3. Organoleptic characteristics of samples.

\begin{tabular}{lccccc}
\hline Sample & $\begin{array}{c}\text { Taste } \\
(1)\end{array}$ & $\begin{array}{c}\text { Odour } \\
(2)\end{array}$ & $\begin{array}{c}\text { Colour } \\
(3)\end{array}$ & $\begin{array}{c}\text { Look } \\
(4)\end{array}$ & $\begin{array}{c}\text { Overall } \\
\text { appearance (5) }\end{array}$ \\
\hline Carrot & + & + & + & + & 100 \\
Parsley root & + & + & + & + & 100 \\
Celery root & + & + & + & + & 100 \\
Potato & + & + & + & + & 100 \\
\hline
\end{tabular}

Key:

(1) Excellent (+) 25 points, indefinite (0) 10 points, bad (-) 0 points

(2) Excellent $(+) 25$ points, indefinite (0) 10 points, bad (-) 0 points

(3) Like a fresh sample (+) 25 points, bright (f) 10 points, dark (0) 0 points

(4) Good (+) 25 points, bad (-) 0 points 
Rehydration coefficient:

$$
M_{r} / m_{0}=\left(W_{r}+1\right) /\left(W_{0}+1\right) .
$$

\section{Discussion}

Dried vegetables are used in all sorts of industrial food products, especially in instant foods (Vrac \& Gruner 1994; Garcia-Reverter et al 1994; Swasdisev \& Soponronnarit 1999), which have a very short preparation time (between 5 and 15 minutes). Therefore, it is very important that dried products have short rehydration times and retain the characteristics of fresh vegetables (size of samples, colour, taste, odour etc.). After they have been dried, vegetables should contain as much moisture as the storage conditions allow so that there is no interaction between the moisture content and other components which have been added to the product (Soponronnarit et al 1997). In the conventional drying processes the drying time is between 3 and 6 hours. At those conditions it is hard to keep the taste or the colour (because of the enzyme browning) unchanged. In the fluid bed dryers the drying time is greatly shortened and all the particles are equally dried while they float in the fluidized bed (Kwauk et al 2000).

During the fluidisation process the batch is fluffed with a stream of warm fluid until all the pieces float in the fluid and form a homogenous bed. This homogenised bed of vegetable pieces is mixed and stirred and at some point of time the surfaces of all the pieces are exposed to the same conditions of drying.

Pressure drop, linear air speed at the column exit and the height of bed has been measured for each vegetable (potato, carrot, celery root and parsley root). Vegetables have been dried at different temperatures: 60, 80 and $1000 \mathrm{C}$. Drying times have varied depending on the sort of vegetable, its mass and the size of the pieces (figure 2).

The shortest fluidisation time has been for celery $(\tau=1200 \mathrm{~s})$, the longest for potato ( $\tau=3000 \mathrm{~s}$ ) which may be due to the starch content inside them. Starch from the vegetables, during fluidisation, floats on the surface and slows down the exit of the water from the inside. The content of starch in potatoes is $18.9 \%$ compared in carrots $(9.1 \%)$, which is more than double, and this can affect the drying rate. Carrots $(\tau=2000 \mathrm{~s})$ and parsley values ( $\tau=2400 \mathrm{~s}$ ) are very close to each other which can be explained on the basis of their similar

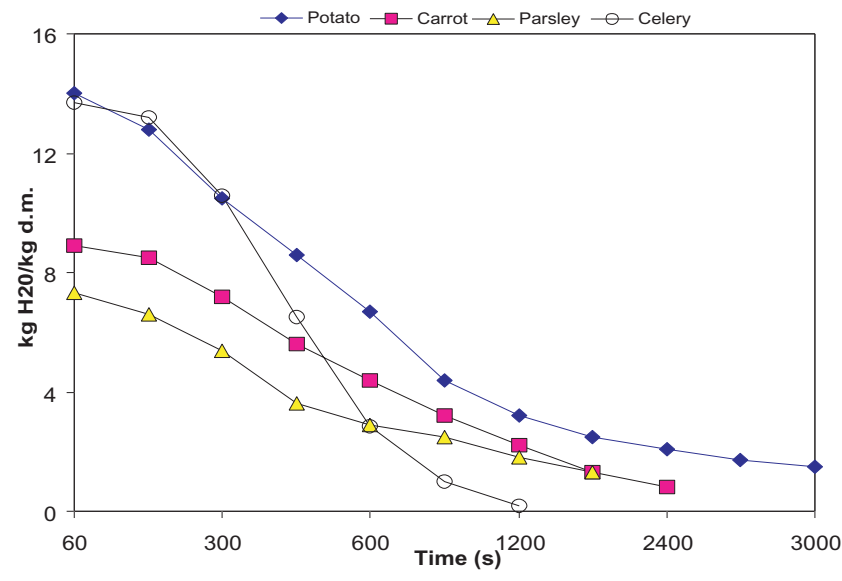

Figure 2. Duration of vegetable drying. 


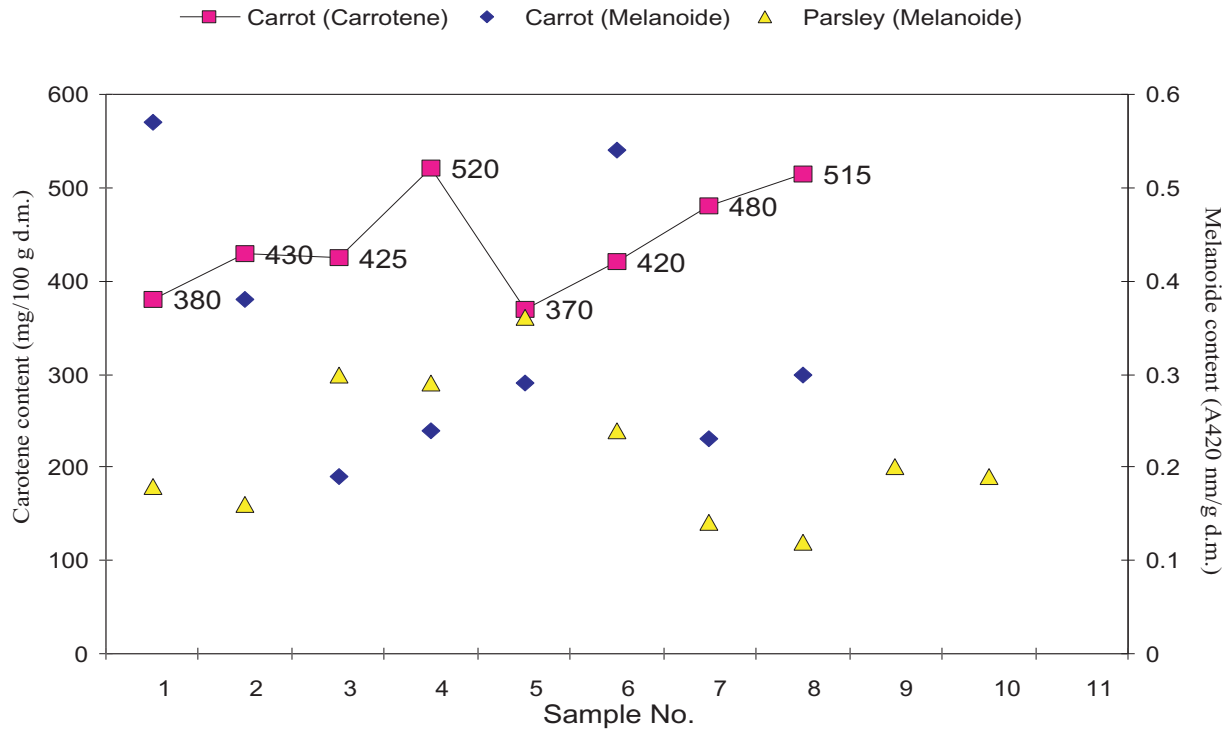

Figure 3. Melanoid and carotene content in carrots and parsley.

consistencies. As far as water content is concerned, these vegetables lose more water than the other two, depending on the sugar content, especially in the dried product. Also the melanoid content (AACC 1998) in parsley is lower than it is in carrots, which can also affect the drying process (figure 3 ).

Figure 4 shows that the fluidisation speed depends on the mass of the piece and its geometry. With smaller pieces the fluidized bed is porous and fluidisation is reache earlier. All the

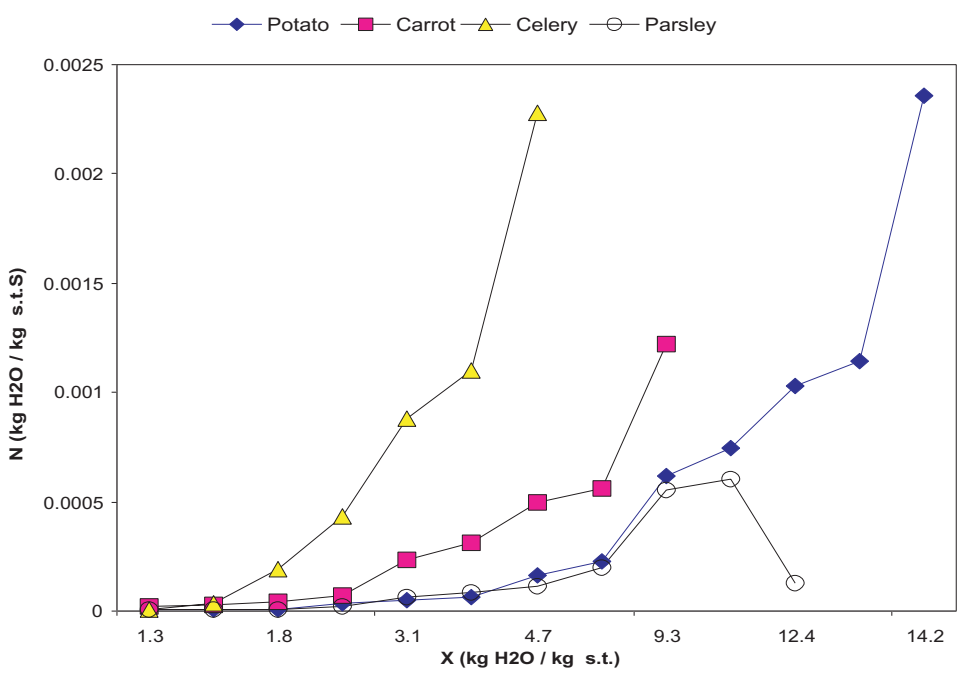

Figure 4. Fluid bed drying rates for different vegetables. 


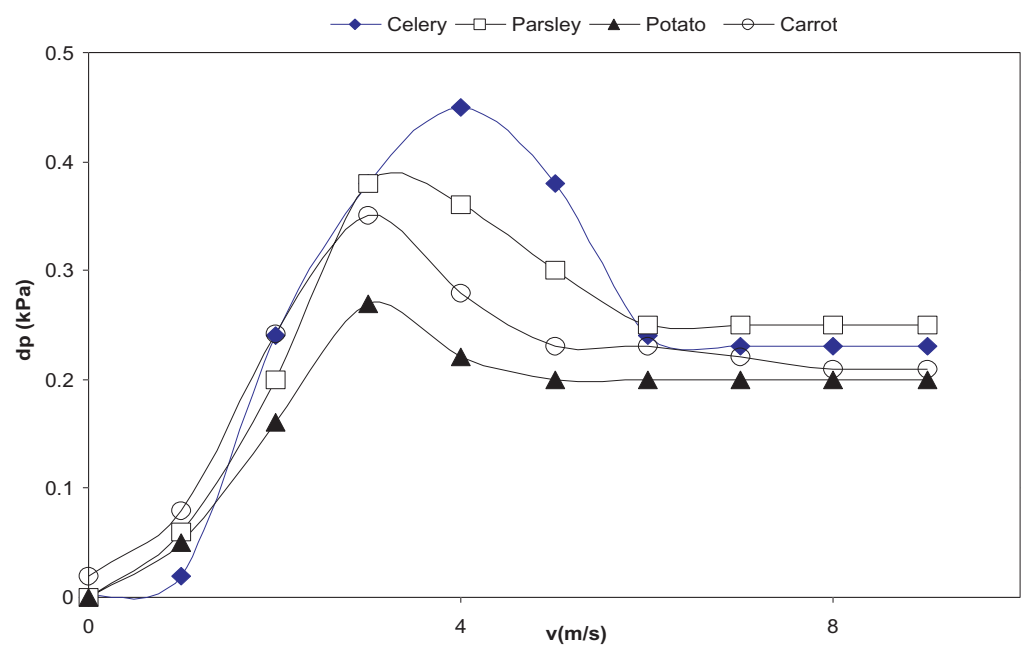

Figure 5. Pressure drop and critical velocities of air for fluidised bed of vegetables.

analysed pieces belong to D group (density around $1-5 \times 10^{7} \mathrm{gcm}^{-3}$ ) according to Geldart (1973) (large pieces between 1000 and $2000 \mu \mathrm{m}$ ) and are in the area where the pieces take on the characteristics of the fluidized bed. Hydrodynamic characteristics of the pieces are the same as found in the literature (Soponronnarit et al 1997; Kwauk et al 2000) and in some prior results (Bauman \& Tripalo 1984; Bobić et al 1986)

Minimal point of fluidisation occurrs sooner with those pieces that have lower mass and density. Under these conditions energy consumed has been lower, at the same temperature and fluid speed, regardless of the shape of the pieces, while drying time (Formisani et al 2001) has been shorter than with other methods. Pressure drop and critical air speeds for fluidised beds of different vegetables are shown in figure 5 .

Pressure drop is lower for potatoes $(\Delta p=0.21 \mathrm{kPa})$ and is highest for celery $(\Delta p=$ $0.46 \mathrm{kPa})$. The values for carrots, $(\Delta p=0.35 \mathrm{kPa})$ and parsley $(\Delta p=0.29 \mathrm{kPa})$ are very close (drying times, fluid velocity, minimal point of fluidisation) to literature data (Hilal et al 2001).

Tests with respect to rehydration and quality before usage of vegetables are more than satisfactory. All four samples reached a high degree of rehydration.

Rehydration times were varied so we could obtain the best time, chosen according to the best product obtained. Rehydration time was also shorter than in any other drying method (shown in figures 6 and 7). It can be seen that dried carrot cubes showed an increase in carotene. This can be explained by assuming that it was easier to extract carotene (AOAC 1995) from dried vegetable structure than from fresh cells or by assuming a cis-trans isomerisation of carotenoid pigments. All samples dried on fluid beds showed much less colour degradation than the ones dried conventionally. When different samples of carrots were examined (figure 7), it was seen that there was some effect of the variety of carrots used, therefore the results varied greatly. Parsley samples dried in a very short time ( 80 and 65 minutes) and they gave product of excellent rehydration ratio (after only 5 minutes rehydration ratios were 7.2). The dried cubes retained the original white colour. With celery, it took 90 minutes at $60-65^{\circ} \mathrm{C}$ to achieve about $93 \%$ of dry matter content and rehydration ratios of over 5 after 10 minutes cooking in water were obtained. Samples that were dried at higher temperatures needed some 


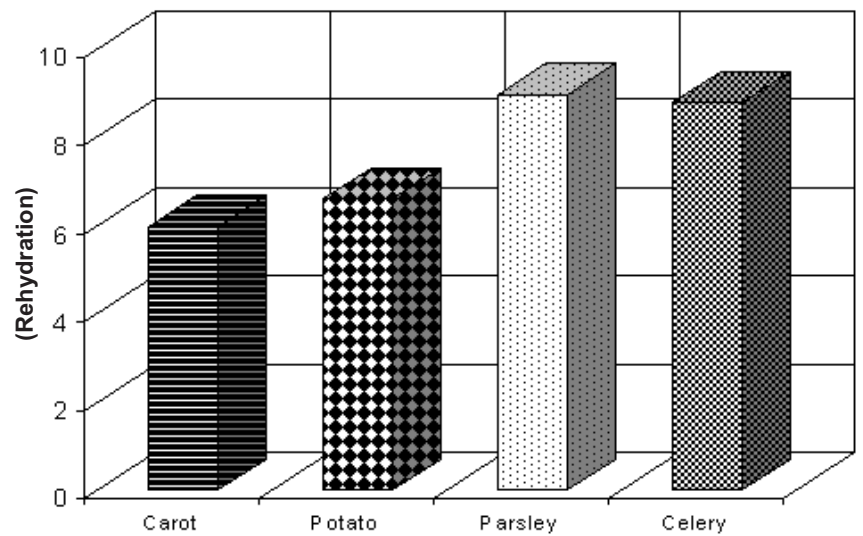

Figure 6. Rehydration ratio for different vegetables dried in fluidized beds.

more time to reach the same dry matter content and they turned brown. It can be seen that treatment with $\mathrm{SO}_{2}$ is of great importance if the white colour of dried samples is to be retained, and that results are better with longer treatment times (30 minutes).

Organoleptic characteristics which are shown in table 3 show that rehydrated vegetables dried on a fluidized bed are of first quality with excellent taste, and the closest possible to fresh ones.

\section{Conclusion}

Drying of vegetables on a fluidised bed offers numerous advantages compared to other drying methods, the most significant being that the time needed to dry materials down to low moisture contents is much shorter.

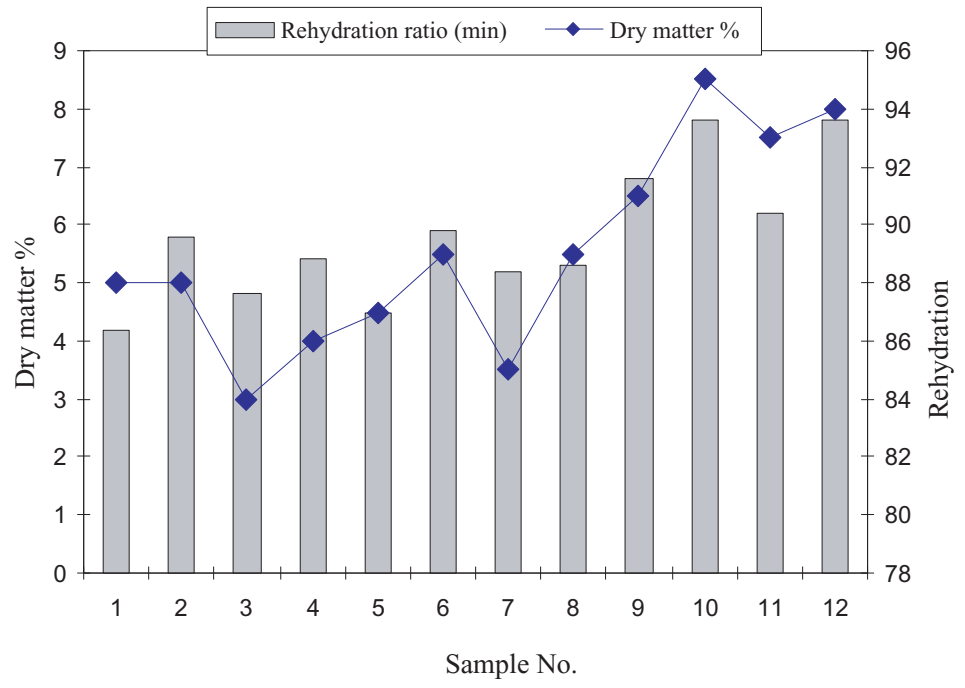

Figure 7. Dry matter and rehydration ratio for carrots. 
With drying on a fluidised bed it is possible to establish the optimal temperature for each step in the process of drying for each vegetable used. Dried vegetables, regardless of their shape (chunks, squares, circles) and size reach a defined amount of moisture in a much shorter time (up to 50\%) than is needed in standard drier types. The product quality, as well as its rehydration time fulfils the goals set at the beginning of our work. Depending on the pre-treatment applied, rehydration times are up to $30 \%$ better than other methods normally used and the quality is very uniform. Lower drying temperatures can be used and substantial energy saving is possible. Shorter drying times and pretreatments used give products with very good organoleptic properties, good colour and good rehydration times. Experiments on carrots indicate that for every sort of vegetable there is a better combination of pretreatment, starch concentration and treatment time that, with exact drying regimes, gives optimal products. Therefore, we can say that drying on fluidised beds is the most reliable and the most economical method for drying vegetable pieces.

It would be interesting to carry out further experiment on a pilot-scale continuous fluid bed drier to gather all pertinent data for a scale-up.

\section{List of symbols}

$C_{1} \quad$ drying velocity coefficient;

$M_{\text {ost }} \quad$ weight of dried sample $(\mathrm{kg})$;

$M_{\mathrm{r}} \quad$ weight of drip-dried rehydrated sample $(\mathrm{kg})$

$m_{\mathrm{o}} \quad$ mass of single sample $(\mathrm{kg})$

$N \quad$ drying velocity $\left(\mathrm{kg}_{\mathrm{H}_{2} \mathrm{O}} \mathrm{kg}_{\text {d.m. }}^{-1} \mathrm{~s}^{-1}\right)$;

$m_{\text {d.m. }} \quad$ dry matter, mass $(\mathrm{kg})$;

$R_{\mathrm{o}} \quad$ rehydration ratio;

$v \quad$ velocity $\left(\mathrm{m} \mathrm{s}^{-1}\right)$;

$v_{1} \quad$ minimal fluidisation speed $\left(\mathrm{m} \mathrm{s}^{-1}\right)$;

$W_{0} \quad$ water content in fresh material $(\mathrm{kg} / \mathrm{kg})$;

$W_{\mathrm{r}} \quad$ water content in rehydrated material $(\mathrm{kg} / \mathrm{kg})$;

$x \quad$ moisture $\left(\mathrm{kg}_{\mathrm{H}_{2} \mathrm{O}} \mathrm{kg}_{\mathrm{d} . \mathrm{m} .}^{-1}\right)$;

$x_{1} \quad$ initial moisture $\left(\mathrm{kg}_{\mathrm{H}_{2} \mathrm{O}} \mathrm{kg}_{\text {d.m. }}^{-1}\right)$;

$x_{\mathrm{r}} \quad$ relative moisture $\left(\mathrm{kg}_{\mathrm{H}_{2} \mathrm{O}} \mathrm{kg}_{\mathrm{d} . \mathrm{m}}^{-1}\right)$;

$\beta \quad$ coefficient;

$\rho \quad$ density $\left(\mathrm{kg} \mathrm{m}^{-3}\right)$;

$\rho_{1} \quad$ bulk density $\left(\mathrm{kg} \mathrm{m}^{-3}\right)$;

$\tau \quad$ drying time (s).

\section{References}

AOAC 1995 Official Methods of Analyses of AOAC (Assoc. of Anal. Communities) (16th edn) Official Method for Carotenoids. No. 941.15; 45, Arlington, USA, p.4

AACC 1998 Approved methods for vegetable browning 9th edn (Haverlee, Belgium: Am. Assoc. Cereal Chemists, AACC) vol. 1, pp 56-70

Bauman E, Tripalo B 1984 Determination of characteristics of vegetable drying. 4th Yugoslavian, Austrian, Italian Chemical Engineering Conference, Grado, Italy (eds) P Alessi, L Kikic, pp 27-35

Bobić Z, Bauman E, Djakovic Z 1986 Dehydration of vegetables on homogeneous fluidized beds in optimum conditions. First Yugoslavian, Austrian Italian Conference, pp.659-666 
Formisani B et al 2001 A fundamental approach to the phenomenology of fluidisation. Chem. Eng. Sci. 56: 109-119

Garcia-Reverter J, Sanjuan R, Bon J, Mulet A 1994 Low temperature blanching affects firmness and rehydration of dried cauliflower florets. J. Food Sci. 59: 1181-1183

Geldart D 1973 Types of gas fluidisation. Powder Technol 7: 285-293

Hilal N et al 2001 Effect of bed diameter, distributor and inserts on minimum fluidisation velocity. Chem. Eng. Technol. 24: 161-165

Kožiškova B 1983 Heat transfer in a flow of consistent food materials. Ph D thesis, Czech Technical University, Prague

Kwauk M et al 2000 Particulate and aggregated fluidisation - 50 years in retrospect (review). Powder Technol. 111: 3-18, 21

Le Maguer M, Jelen P (eds) 1986 Food engineering and process applications. Volume 1. Transport phenomena (New York: Elsevier Appl. Sci.)

Soponronnarit S, Pongtornkulpanich A, Prachayawarakorn S 1997 Corn quality after drying by fluidisation technique at high temperature. Drying Technol. 15: 2577-2586

Swasdisev T, Soponronnarit S 1999 Drying of chopped spring onion using fluidisation technique. Drying Technol. 17: 1191-1199

Troller J A, Christian J H B (eds) 1978 Water activity and food (New York: Academic Press)

Vrac N, Gruner M 1994 Effect of fluidized bed drying on properties of dehydrated apples. Nahrung 38: $149-157$ 